\section{Pleistocene and Holocene climates in Africa}

IN examining the question of Pleistocene and Holocene climatic fluctuations in North-West Africa, Sarnthein et al. ${ }^{1}$ distinguish between hypotheses that suggest distinct latitudinal shifts and those assuming stable latitudinal positions but contraction and expansion of the arid zone, and they cite Nicholson and Flohn ${ }^{2}$ as an example of the former. This is clearly incorrect. We do indicate such shift at $18,000 \mathrm{yr}$ BP, but not for later periods; and we clearly show a pronounced contraction of the arid zone during the climatic optimum at $6,000 \mathrm{yr}$ BP. We do suggest that both a shift in the position and changes in intensity of the major circulation features are responsible for African rainfall changes in the late Pleistocene and Holocene.

Sarnthein et al. ${ }^{1}$ cite primarily two lines of evidence of 'stable' latitudinal positions of circulation features. The first, concerning the location of the westerly wind belt over North-West Africa, is contradicted by recent findings ${ }^{3}$, which suggest it extended to $20-40^{\circ} \mathrm{N}$ at $18,000 \mathrm{yr}$ BP and at present. Furthermore, the main Pleistocene displacement of that zone would probably have been during the summer and its southern most position (winter months) may not have differed much from present. The second piece of evidence is the mean position of the 'Harmattan' dust outbreaks, which are related to the midtroposphere jet. The term 'Harmattan' is misused: today it is generally understood to be the surface, northeasterly tradewind flow and not the upper-level easterlies. Furthermore, one cannot conclude, as those authors did, that the position of the ITCZ (intertropical convergence zone) is necessarily coincident with the position of the dust carried by the 'Harmattan' flow (or jet). This flow is a direct consequence of the temperature gradient between the Sahara and the relatively cooler and more humid air further south ${ }^{4}$. As long as the southern Sahara exists, and given the fixed Atlantic boundary to the south, the position of this easterly flow aloft (the mid-tropospheric jet) is relatively fixed. The ITCZ, on the other hand, is both dynamically and thermally determined and its position most directly reflects inter-hemispheric thermal differences, which did vary greatly throughout the late Pleistocene and Holocene. Although at present the ITCZ and related disturbances over West Africa coincide with the mid-tropospheric jet and Harmattan, they need not necessarily coincide.

The shear associated with the jet is critical for the formation of West African disturbances ${ }^{4}$ and a weakened easterly flow could conceivably, as suggested by Sarnthein et al. $^{1}$, have been a factor in sub-Saharan aridity $\sim 18,000 \mathrm{yr}$ BP. Indeed, this may also have been a factor in the recent Sahel drought ${ }^{5}$. However, the authors present no evidence of a stable position of other circulation features, such as the westerlies or the ITCZ, and it is highly unlikely that the latter was not displaced towards the equator in late Pleistocene, when glaciation and temperature changes were most pronounced in the Northern Hemisphere and interhemispheric thermal contrast must have been minimal.

\section{SHARON E. NICHOLSON} Graduate School of Geography, Clark University, 950 Main Street, Worcester, Massachusetts 01610, USA

1. Sarnthein, M., Tetzlaff, G., Koopman, B., Wolter, K. \& Pflaumann, V. Nature 293, 193-196 (1981).

2. Nicholson, S. E. \& Flohn, H. Climat. Change 2, 313-348 (1980).

3. Street-Perrott, F. A. \& Roberts, N. in Variations in the Global Water Budget (eds Street-Perrott, F. A., Beran, M. \& Ratcliffe, R. A. S.) (Reidel, Dordrecht, in the press).

4. Holton, J. R. An Introduction to Dynamic Meteorology (Academic, New York, 1979).

5. Kanamitsu, M. \& Krishnamurti, T. N. Mon. Weath. Rev. 106, 331-347 (1978).

TETZLAFF, SARNTHEIN AND WOLTER REPLY - The comments of Nicholson give us the opportunity to clarify possible misunderstandings of our concepts and conclusions on the underlying causes of climatic change in North Africa ${ }^{1}$. Nicholson particularly questions our evidence of 'stable' latitudinal positions of circulation features.

With regard to the extension of the westerlies, we basically agree with Nicholson, although we did not say too much about it in our article ${ }^{1}$ and cited only indirect evidence. The westerlies indeed extended to $20-40^{\circ} \mathrm{N}$ over North-West Africa, in both periods considered, not only at 18,000 yr BP, but also at the present time. Nevertheless, average westerly wind vectors are substantiated on land only by proxy data ${ }^{2}$ for precipitation due to synoptic disturbances in the westerlies.

In the Atlantic, the subtropical gyre and the coastal upwelling off the western Sahara essentially did not have a more southerly position around $18,000 \mathrm{BP}$ and this provides additional evidence for a stable southern fringe of the westerlies during both winter and summer average seasons $^{3}$. This contradicts a general equatorward displacement of the climatic belts south of the present westerlies in the Northern Hemisphere during cold stages, as suggested by Nicholson.
The other feature questioned-the relationship between the mean position of dust outbreaks and the position of the middle and lower tropospheric part of the ITCZ, in particular the monsoonal front-needs a deeper discussion of the meterological structures. Along a trajectory in the continental trades southwards, the average temperature of the lower troposphere would continuously increase ${ }^{4,5}$, at $\sim 18,000 \mathrm{BP}$ as well as at present. The middle tropospheric easterly winds which carry the main Saharan dust outbreaks require the opposite horizontal gradient. This means a southward sloping isobaric plane on the southern fringe of the subtropics. Like other authors ${ }^{6}$, we call these easterlies 'Harmattan' for our convenience.

We again agree with Nicholson that such an equatorward temperature decrease can be produced only by the cooler tropical air masses, the northern boundary of which is called monsoonal front and coincides with the ITCZ near the surface over land at the present. Finally, the maximum slope of the isobaric surface can also result in barotropic instability providing the energy for the easterly waves. This implies that the easterly (Harmattan) winds, the lower tropospheric parts of the ITCZ (Fig. $1 a$ in ref. 1) and the easterly waves (including the dust transport in their wake) are three different effects of the same dynamic structure and their positions are necessarily closely related. We feel that some authors ${ }^{5,7}$ imply a connection between the positions of the maximum rainfall zone and the northern boundary of the monsoonal air masses. They are assumed to be coupled by the downdrafts of the storms in the rainfall zone. However, recent findings ${ }^{5}$ do not confirm such a direct relationship. Of course, the historical position of the ITCZ in North Africa is averaged over a number of cyclic processes on the synoptic, annual and long-term climatic scale, but it is not necessarily coupled with interhemispheric temperature differences as postulated by Nicholson. A separate dynamic ITC (intertropical convergence) equatorwards of the monsoonal front over Africa at $18,000 \mathrm{yr} \mathrm{BP}$ is theoretically possible, but not probable. As a result we consider our conclusions ${ }^{1}$ valid. They strongly suggest that the dust-carrying winds, the Harmattan and the Trades, the subtropical anticyclone and also the ITCZ near the surface were not displaced equatorwards in western North Africa during the last glacial stage. Thus the fluctuations in the degree of sub-Saharan aridity/humidity should be related to factors such as the intensity and frequency of rain-bearing disturbances ${ }^{8}$ rather than to the average surface position of the ITCZ. 